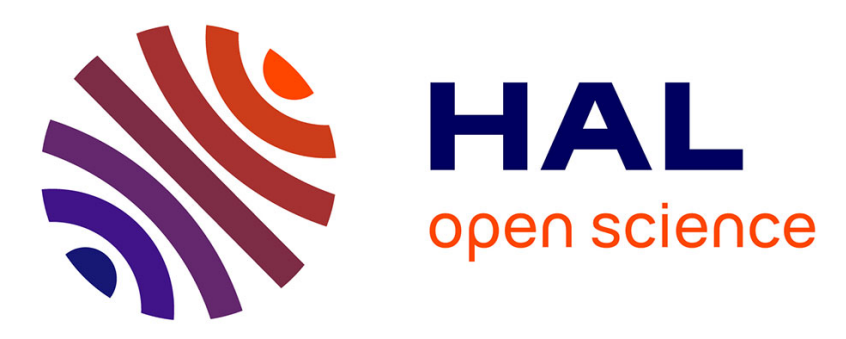

\title{
Strategy of macromolecular grafting onto a gold substrate dedicated to protein-protein interaction measurements.
}

Virginie Mansuy-Schlick, Régis Delage-Mourroux, Michèle Jouvenot, Wilfrid Boireau

\section{To cite this version:}

Virginie Mansuy-Schlick, Régis Delage-Mourroux, Michèle Jouvenot, Wilfrid Boireau. Strategy of macromolecular grafting onto a gold substrate dedicated to protein-protein interaction measurements.. Biosensors and Bioelectronics, 2006, 21 (9), pp.1830-7. 10.1016/j.bios.2005.11.021 . hal-00446991

\section{HAL Id: hal-00446991 https://hal.science/hal-00446991}

Submitted on 14 Jan 2010

HAL is a multi-disciplinary open access archive for the deposit and dissemination of scientific research documents, whether they are published or not. The documents may come from teaching and research institutions in France or abroad, or from public or private research centers.
L'archive ouverte pluridisciplinaire HAL, est destinée au dépôt et à la diffusion de documents scientifiques de niveau recherche, publiés ou non, émanant des établissements d'enseignement et de recherche français ou étrangers, des laboratoires publics ou privés. 
Strategy of macromolecular grafting onto a gold substrate dedicated to protein protein interaction measurements

V. Mansuy-Schlick, R. Delage-Mourroux, M. Jouvenot and W. Boireau*

Equipe «Estrogènes, Expression Génique et Pathologies du Système Nerveux Central», Université de Franche-Comté, U.F.R. Sciences et Techniques, IFR 133, 16 Route de Gray, 25030 Besançon cedex, France.

* Institut FEMTO-ST, Département LPMO, UMR6174 du CNRS, 32 Avenue de l'Observatoire, 25044 Besançon, France. To whom correspondence should be addressed (emailwboireau@lpmo.edu)

\section{Abstract}

Many biotechnology applications use proteins immobilized on surface. For biosensor, the sensing layer is a key component interfacing the transducer and the sample. Strategies employed to activate the bidimensional surface act directly on the performance of the biosensor. In this paper we propose a novel strategy for engineered proteins self-assembly. Our original supramolecular structure allows a direct and fast covalent attachment of proteins onto bare gold substrate through a homobifunctional crosslinker, 1,4-Di-[2'pyridyldithio)propionamido]butane (DPDPB). In this work, engineered proteins and linkerprotein complexes were synthesized and characterized by gel electrophoresis, chromatography and spectroscopy experiments. Macromolecular construction "DPDPB-GST tag-GEC1 protein" was conceived in order to guarantee a 2D architecture enhancing the capabilities of the target (tubulin) to recognize its partner (GEC1). Surface plasmon resonance measurements clearly showed potential of this particular self-assembled protein layer 
compared to a commercial immunosensor interface. At the concentrations tested, the recognition process occurs between tubulin and the immobilized GEC1; moreover enhanced binding was obtained with the home-made 2D sensing layer more than with 3D carboxymethyl dextran matrix.

Key words: Self-assembled-monolayer (SAM), DPDPB, Protein immobilization, Surface Plasmon Resonance (SPR), GEC1, tubulin. 


\section{1) Introduction}

In the biosensor field, protein immobilization is a crucial point conditioning the properties of specificity, stability and usability. From the point of view of protein-protein interactions and kinetic measurements, immobilization induces heterogeneous binding characteristics compared to bio-recognitions in solution. Thus, strategies employed require high level of control of the macromolecular architecture in order to prevent steric hindrance and constraints of mass transfer. Most of strategies of functionalization deal with polymer deposition onto the biosensor surface as carboxymethyl dextran. Chemical modifications of this 3D matrix are well known and have been used in many cases in order to immobilize receptors, enzymes, and antibodies through their amino or sulfhydryl residues (Sonezaki et al., 2000). However, these techniques have some limitations in exposing ligands far from the surface, since they introduce diffusion restrictions inside the coating and deviations of the kinetic models (Sadana, 2001; Yarmush et al., 1996). At present, self assembled monolayers (SAMs) of macromolecular species on inorganic surfaces are used in extending domains especially in protein chips (Park et al., 2000). Bi-dimensional grafting is a promising way to get a specific and sensitive sensor at the condition that highly controls of supramolecular constructions are performed (Boireau et al., 2005a; Nieba et al., 1997; Shriver-Lake et al., 1997); SAM approach can bring enhanced performance in selectivity compared to commercial hydrogel biochip (Frederix et al., 2003).

Many commercial bi-functional linkers are available and are normally used for linking two different macromolecules. For example, 1,4-Di-[2'-pyridyldithio)propionamido]butane (DPDPB) is a homo-bifunctional crosslinker that reacts specifically with sulfhydryl groups. It is commonly employed to produce protein-protein cross bridges or to confer disulfide links with modified nucleic acids (Boireau et al., 2005b). As previously demonstrated with other cross linkers, the intrinsic disulfide links allows chemisorption of the sulfhydryl terminus onto 
a metallic template leading to a highly controlled monolayer of macromolecular species (Park and Kim, 1998). In our laboratory, we have recently identified a novel gene called GEC1 (Vernier-Magnin et al., 2001). GEC1 has been shown to associate with tubulin and microtubules and may be involved in $\mathrm{GABA}_{\mathrm{A}}$ receptor trafficking in synapses along the cytoskeleton (Mansuy et al., 2004; Wang and Olsen, 2000; Wang et al., 1999). The GABA receptor is the main receptor in the central nervous system and is a target for drugs like Valium and Xanax, frequently used for anxiety, mood alteration, sleep, or epilepsy (Kennedy, 2000). Thus, it is very important to establish whether this protein play a role in the transport processes. To demonstrate the interaction between GEC1 and tubulin, GST pull down and traditional BIAcore assays have been performed using recombinant purified GST-GEC1 and tubulin purified from microtubule-associated protein (Mansuy et al., 2004).

In this study, we present a new method of protein immobilization leading to selfassembled protein monolayer reconstitution onto a gold surface in order to characterize of GEC1-tubulin interactions by surface plasmon resonance.

\section{2) Material and methods}

\subsection{Construction of the GST fusion expression vector: GST-GEC1}

Plasmids encoding glutathione S-transferase (GST)-GEC1 was generated by PCR using the human full-length pGEMT-GEC1 as a template. Reactions were performed using Taq polymerase from Life Technologies Inc. (Cergy Pontoise, France) according to the manufacturer's recommendations.

The following PCR primers were used $(\mathrm{f}=$ forward primer, $\mathrm{r}=$ reverse primer):

GEC1 (1)f: 5'-CGGAATTCCGATGAAGTTCCAGTACAAGGAG-3';

GEC1(117)r: 5'-CCGCTCGAGCGGTCATTTCCCATAGACACTCTC-3'. 
PCR fragments were purified, digested with EcoRI and XhoI, and cloned into the EcoRI/XhoI sites of pGEX-4T-2 (Amersham Biosciences, Orsay, France) in order to generate the pGEX4T-2- GEC1 plasmid. The nucleotide sequence of this plasmid was confirmed by sequencing.

\subsection{Protein expression and purification}

The full-length gec1 was cloned in pGEX-4T-2 (Pharmacia) and expressed as a fusion protein with the glutathione S-transferase (GST) moiety on the N-terminus. Escherichia coli strain DH5 $\alpha$ or BL21 containing the expression plasmid were grown to OD $600 \mathrm{~nm}$ of 0.8 , induced by $0.8 \mathrm{mM}$ isopropyl D-thiogalactopyranoside for $2 \mathrm{~h} 30^{\prime}$, homogenized in phosphatebuffered saline (137 mM NaCl, $2.7 \mathrm{mM} \mathrm{KCl,} 10 \mathrm{mM} \mathrm{NaHPO}_{4}$ and $1.7 \mathrm{mM} \mathrm{KH}_{2} \mathrm{PO}_{4}, \mathrm{pH} 7.4$ ) with $1 \%$ Triton X-100 and protease inhibitors, and loaded onto glutathione sepharose (Amersham). The GST fusion proteins were eluted by $10 \mathrm{mM}$ glutathione/ $50 \mathrm{mM}$ Tris, $\mathrm{pH}$ 8.0. Protein concentration was determined by the Lowry method (Lowry et al., 1951). The purified proteins were analyzed by sodium dodecyl sulfate (SDS)-polyacrylamide gel electrophoresis (PAGE).

\subsection{GST fusion protein modification procedure}

The protein GST-GEC1 and GST in phosphate buffer saline were treated for 15 minutes with dithiothreitol (DTT) 10-fold molar excess at $0.1 \mathrm{M}$ to eliminate GST dimerized forms. DTT was separated using a gel filtration column filled with Sephadex G25 (Sigma Aldrich). Then, the fusion proteins were treated with a 100-fold molar excess of DPDPB (1,4Di-[2'-pyridyldithio]propionamido)butane which is used as a homobifunctional reagent for 3 hours at $25^{\circ} \mathrm{C}$. Unreacted DPDPB was separated using a gel filtration column filled with Sephadex G25. To confirm that unreacted DPDPB was well separated from the GST-fusion protein - DPDPB complex, excess of DTT (up to 20:1 mole) was incubated 5 minutes with 
the sample. DTT breaks the disulfide bond within the fusion protein-DPDPB complex and releases thiopyridine that is absorbed at $344 \mathrm{~nm}$. Protein separation and percentage of modified proteins were monitored with a $\lambda 900$ spectrophotometer (Perkin Elmer) by absorbance change at $344 \mathrm{~nm}$. Indeed, bound DPDPB species were determined with the following formula:

$$
\begin{gathered}
{[\text { bound } D P D P B]=[\text { free thiopyridine }]=\frac{\Delta O D}{\varepsilon}} \\
\varepsilon=\mathbf{s o s 0} \mathbf{~ M}^{-1} \cdot \mathbf{c m}^{-1}
\end{gathered}
$$

\subsection{SPR experiments}

BIAcore experiments were performed with Biacore ${ }^{\circledR} 3000$ apparatus. All of the experiments were carried out at $25^{\circ} \mathrm{C}$ in Hepes Buffer Saline or HBS (10 mM HEPES, 0,15M $\mathrm{NaCl}, 50 \mu \mathrm{M}$ EDTA, $0,005 \% \mathrm{P} 20, \mathrm{pH} 7.4)$ with a flow rate between 5 and $30 \mu \mathrm{l} / \mathrm{min}$. All the samples were prepared and diluted with HBS buffer. Two different kits were used: CM5 (carboxymethyl dextran matrix) and SIA-kit (bare gold substrates). The immobilization degree of proteins and the level of interactions in Biacore SPR technology are reported in a sensorgram (response unit (RU) versus time (in seconds)). 1000 RU correspond to a shift in resonance angle of 0.1 degree. Calibration of the apparatus gives a correlation between the shift in angle and the mass deposition on the surface of the biochip of $0.1^{\circ} \sim 1 \mathrm{ng} / \mathrm{mm}^{2}$ (Stenberg et al., 1991).

\subsection{Protein immobilization on carboxymethyl dextran surface}

The immunosensor on the CM5 sensor chip was prepared as previously described (Mansuy et al., 2004). Briefly, anti-GST antibody was immobilized using an amine coupling kit, as described by the manufacturer. The purified protein GST or GST-GEC1 at $1 \mu \mathrm{M}$ was then immobilized using antibody-antigen interactions. Surfaces with approximately $2500 \mathrm{RU}$ of immobilized proteins were used for the interaction analysis. 
2.6. Immobilization of fusion protein - DPDPB complex on bare gold surface

The gold surface was cleaned with octyl glucopyranoside (OG), $20 \mathrm{mM}$ at $20 \mu 1 / \mathrm{min}$ for 1 minute. Fusion Protein-DPDPB complexes were injected and immobilized by DPDPB$\mathrm{Au}$ autoassembly. The injection was performed at $1 \mu \mathrm{M}$ with a constant flow of buffer at 20 $\mu 1 /$ minute for 17 minutes. The immobilized complex was washed with OG for an additional 1 minute.

\subsection{Interaction assays on the BIACORE and data analysis}

Each binding cycle was performed with a constant flow of buffer at $20 \mu \mathrm{l} / \mathrm{min}$. Purified tubulin (Cytoskeleton ${ }^{\circledR}$ ) was injected across the surface at $800 \mathrm{nM}$ for 4 minutes. Once the injection plug had passed the surface, the formed complex DPDPB-fusion GST GEC1 - tubulin was washed with running buffer for an additional 1000 seconds. Data were collected and analyzed using the BIA-Evaluation program 3.0 (BIAcore ${ }^{\circledR}$ ).

\section{Results and discussion}

\subsection{Expression and purification of GEC1}

To perform BIAcore experiments, GST-GEC1 fusion protein and GST were expressed in E. coli and were purified by standard glutathion sepharose affinity chromatography. Coomassie blue staining of SDS-PAGE showed that the purified GST-GEC1 and GST proteins migrated as a single band at approximately $40 \mathrm{kDa}$ and $28 \mathrm{kDa}$ respectively with no detectable contaminating bands (Figure 1).

\subsection{Self-assembly of modified GEC1 onto gold sensor chip}

\subsubsection{GST-DPDPB and GST-GEC1-DPDPB couplings}


We developed an original way of placing the protein assembly directly onto the gold layer of the sensor chip. This approach has been compared with a classical way of biosensor building based on antigen-antibody recognition.

The GST portion of the fusion protein provides four cysteine residues not present in the primary sequence of GEC1 (Figure 2). Sulfhydryl compounds are used as anchor sites in various supramolecular assemblies whether directly through disulfide bridges or through different cross linkers. 1, 4-Di-[2'-pyridyldithio) propionamido] butane (DPDPB) is a homobifunctional crosslinker that reacts specifically with sulfhydryl groups.

The coupling experiment is described below and illustrated in figure 3 . In this experiment, 1.5 nmoles of GST fusion protein in phosphate buffer saline were treated for 15 minutes with a 10 -fold molar excess of dithiothreitol (DTT) at $0.1 \mathrm{M}$ to eliminate dimerized form of GST. DTT was separated using a gel filtration column filled with Sephadex G25. Extemporary, the protein was treated with a 100 -fold molar excess of DPDPB $3 \mathrm{~h}$ at $25^{\circ} \mathrm{C}$. Unreacted DPDPB was eliminated by gel filtration chromatography using a column filled with Sephadex G25. Absorbance data indicate that 1.2 nmoles of GST-DPDPB were obtained after the second gel filtration (data not shown). To determine the yield of GST- DPDPB coupling complex, an excess of DTT $(20 / 1,60 / 1,80 / 1$ by mole) was introduced sequentially to $550 \mu \mathrm{l}$ of the $750 \mu \mathrm{l}$ total sample. Protein separation and percentage of modified proteins were monitored by absorbance change at $344 \mathrm{~nm}$. Values were obtained by subtracting spectrum curves with reference (without DTT) leading to a shift in the optical density at $344 \mathrm{~nm}\left(\Delta \mathrm{OD}_{344 \mathrm{~nm}}\right)$. After incubation 5 min with a 20 -fold molar excess of DTT, a $\Delta \mathrm{OD}_{344 \mathrm{~nm}}$ of 0.074 was obtained (data not shown). The $\Delta \mathrm{OD}_{344 \mathrm{~nm}}$ reached 0.012 and stabilized after adding 60-fold or 80-fold molar excess of DTT (Figure 3). These data indicate that $1.1 \mathrm{nmol}$ of the $1.2 \mathrm{nmol}$ of GST was modified. Therefore, the increase of absorbance at $344 \mathrm{~nm}$ indicated that $92 \%$ of GST is coupled to DPDPB. In four experiments with GST or GST- 
GEC1, the rate of coupling was more than $80 \%$ and macroscopically closer to an equimolecular coupling.

\subsubsection{Supramolecular self-assemblies onto gold chip}

Most of the modified proteins presented a 2-pyridyl-disulfide group that could be used directly as chemical anchor onto the gold substrate. It has been previously demonstrated that it is not necessary to disrupt the disulfide bonds with a reducing agent to get self-assembly processes onto gold substrate (Lee et al., 2004). In a novel process, we proposed to use the strong reactivity of disulfide bonds, bearing the dithiopyridyl group, to form cross bridges between macromolecular complexes and the gold substrate of the sensor chip. Figure 4 shows the procedure performed in the Biacore apparatus to build the biosensor by way of the macromolecular complexes self-assembly. First, the surface was cleaned with a detergent (OG). This process was followed by an injection of DPDPB-GST-GEC1 complexes (step 2). Finally, macromolecular complexes that had not been covalently bound to the gold substrate were removed by OG (step 3). An ideal schematic description of GST-GEC1 immobilization by self-assembly of DPDPB linker onto gold substrate is presented below the sensorgram in figure 3 and transposes analogous to the DPDPB-GST immobilisation process. A strong selfassembly was observed leading to a saturation of the chip bidimensional surface at a level of 2850 RU. As in Stenberg's calibration, the signal was converted to $2.85 \mathrm{ng}$ per square $\mathrm{mm}$ (Stenberg et al., 1991). This value corresponded to a surface coverage of 7 picomoles of protein per square centimeter, i.e close to highly packed monolayer of proteins. We observed for each experiment that up to $80 \%$ of the signal was reached before 120 seconds after injection, indicating the efficiency of this strategy to build a protein monolayer. Moreover, the self-assembled macromolecular complexes tolerated smooth washing used to remove non- 
specific interactions. In our study, we observed a negligible non-specific coupling (less than $5 \%$ response units) easily removed by two pulses of OG.

Homo or heterobifunctional linkers have been previously used to immobilize macromolecular species onto a metallic template. Usually, building of supramolecular layers are performed sequentially with a first step consisting of covering the surface with the linker and a second step consisting of in situ chemical reactivity with the protein or nucleic acid (Hedges et al., 2004; Lee et al., 2004). Few studies propose in vitro synthesis of complexes following by their direct self-assembly onto gold surfaces but, in these cases, the disulphide bridge is initially reduced in order to expose free sulfhydryl residues (Lee et al., 2003; Park and Kim, 1998). We demonstrated that our procedure freed from this additional step and the present study pointed out the simplest way to build bidimensional protein self-assembly onto bare gold substrate.

The kinetics of the self-assembly was compared with a conventional and commercial process. Thus, we performed GST captures through a CM5 sensor chip preliminarily coupled with anti-GST antibodies using an amine coupling kit. In this way, a large excess of antibodies was covalently coupled with the carboxymethyl dextran matrix (data not shown) and monitored during the antibody/antigen recognition. Superimposition of the two association kinetics during the first 120 seconds after injection is represented in figure 5 . Results indicate that self-assembly is at least equivalent to the immuno capture in terms of kinetics and level of association.

\subsection{Studies of GEC1-tubulin interactions}

In order to demonstrate the biorecognition capabilities of the self-assembled monolayer of GEC1, we proceeded to injection of tubulin (Figure 6). As expected, a strong interaction between these two proteins was observed (curve A), whereas the specificity of the 
sensor was magnified through the negligible level of tubulin interactions with a monolayer of GST (curve B). Thus, at submicromolar concentration of tubulin, we observed a significant and specific signal of interaction with less than $11 \%$ of non-specific coupling without any cleaning procedure.

Control of the orientation of the macromolecular probes is essential to obtain a highly specific bidimensional response (Vijayendran and Leckband, 2001). Concerning the supramolecular complex presented herein, the lack of cystein in the primary sequence of GEC1 leads to a directed coupling between DPDPB and the GST tag. Thus, as represented in figure 3, GST tag acts as a macromolecular spacer keeping away GEC1 from the metallic surface. Recently, we have demonstrated the capability of tubulin to associate with GSTGEC1 through a dextran matrix functionalized with anti-GST antibodies (Mansuy et al., 2004). The biorecognition property of the highly ordered 2D protein layer was compared with this classical 3D carboxy methyl dextran matrix by SPR experiments (Figure 7). As illustrated, injections of tubulin at a concentration of $800 \mathrm{nM}$ have been performed for these two biosensing layers covered with the same level of immobilized GST-GEC1 species (2600$2800 \mathrm{RU})$. We observed a significant difference of interaction of these two biological partners. Thus, for the CM5 curve, the plateau was quickly obtained at a rate of coupling that did not exceed 3\%, whereas in the case of the bidimensional architecture, signal of association reached a significant higher level corresponding to $12 \%$ of the saturation.

This difference in performance is mainly due to the limitations of the dextran matrix to present the probe in a homogeneous conformation with its target. CM5 matrix has intrinsic limitations in (i) steric hindrance, (ii) heterogeneities in the density and conformation of probes inside the gel, and (iii) kinetic resistance due to improper molecular orientations and mass transfers causing an apparent decrease in the reaction-rate constant (Schuck, 1997; Yarmush et al., 1996; Nygren et al., 1987). 


\section{Conclusion}

Most of the macromolecular coupling strategies onto biosensor surface layers are based on the deposition, functionalization and activation of polymer cushions with an expected high density of probes. However, strategies of direct coupling onto the bidimensional surface of the sensor may be an interesting alternative if bio-functionalization processes are well controlled.

In this study, we produce a fusion protein "GST tag-protein of interest" containing accessible cystein suitable for the efficient coupling with DPDPB linker. The procedure could be obviously used with proteins already possessing internal accessible cysteins.

We demonstrated that efficient and specific self-assembly can be achieved directly onto bare gold substrate leading to a rapid and simple procedure of the "linker-GST tagprotein of interest" monolayer reconstitution. Moreover, the protein layer formed yields higher coupling rates with biological partner than a classical immunosensor. This original procedure gives a new strategy of macromolecular assembly for numerous applications based on gold sensing layer. 


\section{Acknowledgements}

This research work was supported by a fellowship from Ministère de l'Enseignement Supérieur et de la Recherche (MESR) and by grants from MESR (EA 3922) and Ligue Nationale Contre le Cancer (Comité du Doubs and Comité du Jura).

The authors thank Didier DUPONT from INRA (Poligny, France), Christophe Quétard and Denis To Van from Biacore ${ }^{\circledR}$ International SA for their help for SPR instrumentation. We thank Dr. Paolo Martini for reviewing the English.

\section{Legends for figures:}

\section{Figure 1: Expression and purification of recombinant proteins.}

Expression and purification of recombinant GST-GEC1 (A) and GST (B) proteins: Each protein was expressed in E. coli and purified by glutathione-sepharose affinity chromatography. Homogenate after induction (lane 1), column flow-through (lane 2) and eluate (lane 3) were analyzed by SDS-PAGE and stained with Coomassie blue.

\section{Figure 2: GEC1 and GST amino acid sequences.}

The sequences of GEC1 and GST correspond to GenBank accession number NP_113600 and U78872 respectively. Underlined cystein amino acids are only present in the primary sequence of GST.

\section{Figure 3: Spectrophotometer characterization of GST- DPDPB coupling.}

Spectrophotometer analysis of modified proteins was carried out by monitoring the absorbance at $344 \mathrm{~nm}$. Results presented here correspond to the mathematical subtraction of spectrophotometer data: Spectrum curve (in presence of excess of DTT) minus Reference 
(without DTT) leading to a shift in optical density at $344 \mathrm{~nm}\left(\Delta \mathrm{OD}_{344 \mathrm{~nm}}\right)$. The GST protein modified sample was incubated with an excess of DTT (1/60 or $1 / 80$ by mole) giving a maximum shift in OD of 0.012 at $344 \mathrm{~nm}$.

\section{Figure 4: Self-Assembly of "DPDPB-GST-GEC1” complexes onto gold sensor chip.}

Numbers indicate the steps in the self-assembly of DPDPB-GST-GEC1. 1. Washing of gold substrate by injection of octylglucoside (OG), 40mM in PBS during $60 \mathrm{sec}$, 2. Injection of DPDPB-GST-GEC1 complexes, $1 \mu \mathrm{M}$ in HBS during $1100 \mathrm{sec}$, 3. Removal of unbound complexes by injection of OG, $40 \mathrm{mM}$ in PBS during 60 sec.

Schematic description of DPDPB-GST-GEC1 immobilization by self-assembly of DPDPB linker onto gold substrate is presented below the sensorgram.

Figure 5: Superimposition of two GST-GEC1 immobilization strategies onto sensor chips.

(A) Sensorgram of self-assembly of DPDPB-GST-GEC1 complexes $(1 \mu \mathrm{M}$ in HBS) on gold substrate (SIA-Kit).

(B) Sensorgram of immunocapture of GST-GEC1 $(1 \mu \mathrm{M}$ in HBS) on carboxy methyl dextran substrate pre-coated with anti-GST antibodies (CM5 sensor chip).

Experiments were performed during the first $120 \mathrm{sec}$ after the injection for both substrates.

Figure 6: Specific interactions between tubulin and self-assembled DPDPB-GST-GEC1 complexes.

(A) Association/dissociation curve of tubulin with the DPDPB-GST-GEC1 layer.

(B) Non-specific adsorption of tubulin with DPDPB-GST layer. 
Experiments were performed during the first 240 seconds following injection of tubulin (800 $\mathrm{nM}$ in HBS) for both substrates.

Figure 7: Comparisons of interaction levels of tubulin with two different GST-GEC1 substrates.

Results of specific GEC1-Tubulin interactions on CM5 immuno sensorchip (curve A) and SIA-gold sensorchip (curve B) were superimposed for the same level of GST-GEC1 immobilization.

Injections of tubulin ( $800 \mathrm{nM}$ in HBS) were performed during the first 240 seconds after injection for both substrates. 
Boireau W, Zeeh JC, Puig PE, Pompon D. 2005a. Unique supramolecular assembly of a redox protein with nucleic acids onto hybrid bilayer: towards a dynamic DNA chip. Biosensors and Bioelectronics 20(8):1631-1637.

Boireau W, Duncan AC, Pompon D. 2005b. Bioengineering and characterization of DNAprotein assemblies floating on supported membranes. Methods in Molecular Biology 300:349-368.

Frederix F, Bonroy K, Laureyn W, Reekmans G, Campitelli A, Dehaen W, Maes G. 2003. Enhanced Performance of an Affinity Biosensor Interface Based on Mixed SelfAssembled Monolayers of Thiols on Gold. Langmuir 19(10):4351-4357.

Hedges DH, Richardson DJ, Russell DA. 2004. Electrochemical control of protein monolayers at indium tin oxide surfaces for the reagentless optical biosensing of nitric oxide. Langmuir 20(5):1901-1908.

Kennedy MB. 2000. Sticking together. Proc Natl Acad Sci U S A 97(21):11135-11136.

Lee W, Oh BK, Park SS, Bae YM, Paek SH, Lee WH, Choi JW. 2003. Fabrication of selfassembled protein A monolayer and its application as an immunosensor. Biosensors and Bioelectronics 19:185-192.

Lee W, Lee DB, Oh BK, Lee WH, Choi JW. 2004. Nanoscale fabrication of protein A on selfassembled monolayer and its application to surface plasmon resonance immunosensor. Enzyme and Microbial Technology 35(6-7):678-682.

Lowry OH, Rosebrough NJ, Farr AL, Randall RJ. 1951. Protein measurement with the Folin phenol reagent. Journal of Biological Chemistry 193(1):265-275.

Mansuy V, Boireau W, Fraichard A, Schlick JL, Jouvenot M, Delage-Mourroux R. 2004. GEC1, a protein related to GABARAP, interacts with tubulin and $\mathrm{GABA}_{\mathrm{A}}$ receptor. Biochemistry Biophysical Research Communications 325(2):639-648.

Nieba L, Nieba-Axmann SE, Persson A, Hamalainen M, Edebratt F, Hansson A, Lidholm J, Magnusson K, Karlsson AF, Pluckthun A. 1997. BIACORE analysis of histidinetagged proteins using a chelating NTA sensor chip. Analytical Biochemistry 252(2):217-228.

Nygren H, Werthen M, Stenberg M. 1987. Kinetics of antibody binding to solid-phaseimmobilised antigen. Effect of diffusion rate limitation and steric interaction. Journal of Immunological Methods 101(1):63-71.

Park IS, Kim N. 1998. Thiolated Salmonella antibody immobilization onto the gold surface of piezoelectric quartz crystal. Biosensors and Bioelectronics 13(10):1091-1097.

Park IS, Kim WY, Kim N. 2000. Operational characteristics of an antibody-immobilized QCM system detecting Salmonella spp. Biosensors Bioelectronics 15(3-4):167-172.

Sadana A. 2001. A kinetic study of analyte-receptor binding and dissociation, and dissociation alone, for biosensor applications: a fractal analysis. Analytical Biochemistry 291(1):34-47.

Schuck P. 1997. Reliable determination of binding affinity and kinetics using surface plasmon resonance biosensors. Current Opinion in Biotechnology 8(4):498-502.

Shriver-Lake LC, Donner B, Edelstein R, Breslin K, Bhatia SK, Ligler FS. 1997. Antibody immobilization using heterobifunctional crosslinkers. Biosensors and Bioelectronics 12(11):1101-1106.

Sonezaki S, Yagi S, Ogawa E, Kondo A. 2000. Analysis of the interaction between monoclonal antibodies and human hemoglobin (native and cross-linked) using a surface plasmon resonance (SPR) biosensor. Journal of Immunological Methods 238(1-2):99-106.

Stenberg E, Persson B, Roos H, Urbaniczky C. 1991. Quantitative determination of surface concentration of protein with surface plasmon resonance using radiolabeled proteins. Journal of Colloid and Interface Science 143(2):513-526. 
Vernier-Magnin S, Muller S, Sallot M, Radom J, Musard JF, Adami P, Dulieu P, RemyMartin JP, Jouvenot M, Fraichard A. 2001. A novel early estrogen-regulated gene gecl encodes a protein related to GABARAP. Biochemistry Biophysical Research Communications 284(1):118-125.

Vijayendran RA, Leckband DE. 2001. A quantitative assessment of heterogeneity for surfaceimmobilized proteins. Analytical Chemistry 73(3):471-480.

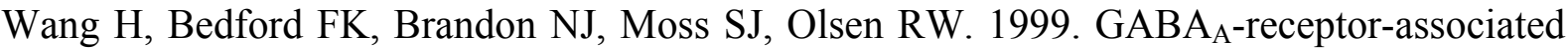
protein links GABA(A) receptors and the cytoskeleton. Nature 397(6714):69-72.

Wang H, Olsen RW. 2000. Binding of the $\mathrm{GABA}_{\mathrm{A}}$ receptor-associated protein (GABARAP) to microtubules and microfilaments suggests involvement of the cytoskeleton in GABARAPGABA $_{A}$ receptor interaction. Journal of Neurochemistry 75(2):644-655.

Yarmush ML, Patankar DB, Yarmush DM. 1996. An analysis of transport resistances in the operation of BIAcore; implications for kinetic studies of biospecific interactions. Molecular Immunology 33(15):1203-1214. 
A

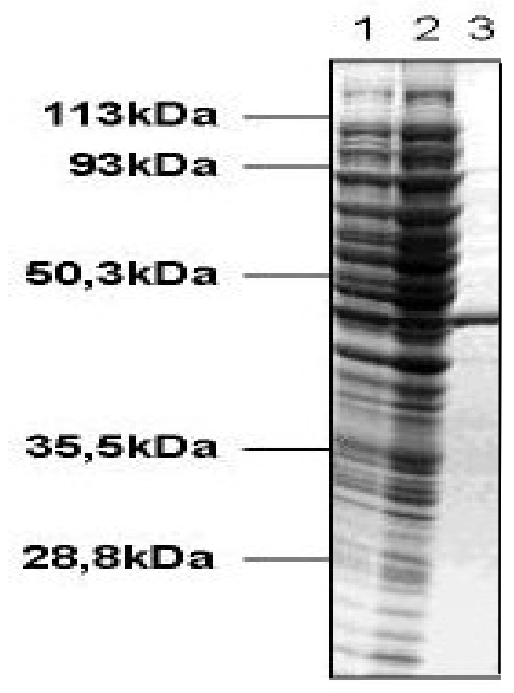

B

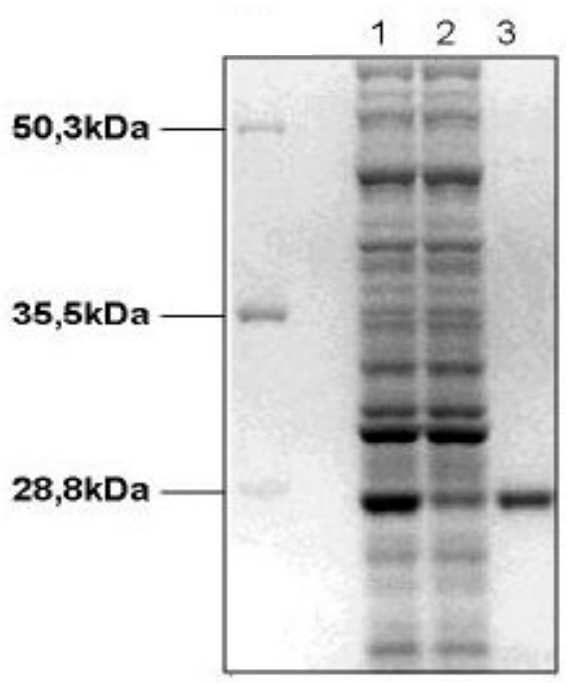

Figure 1 : Expression and purification of recombinant proteins. 


\section{GEC1}

1 MKFOYKEDHPFE YRKKEGEKIRKKY D RUPV IVEKAPKARUPDLDKRKYLVPSDLTUGQF 60

61 YFL IRKR IHLRPED LLLF F FNNT IPP TSÄTMGOL YEDNHEEDYFL YUAYSDESUYGK 117

\section{GST}

1 MSPILGYWKIKGLVOPTRLLLEYLEEKYE HL YERDEGDKWRNKKF ELGLEF PNLPYYID 60

61 GDVKL TOSMA I IRY I ADKHNMLGGCFKERAE ISMLEGAVLD IRYGVSRI AYSKDFETLKV 120

121 DFLSKLFEMLKMF EDRLCHKTYLNGD HUTHPDF ML YD ALDVUL YMD P MCLD AF FKLVCF K 180

181 KRIE IPQD KYLKSSKY I WTLQGWQATFGGGDHPPKSDLEVLFQGPLGSPEFPGRLER 240

241 PHRD 244

Figure 2: GEC1 and GST amino acid sequences. 


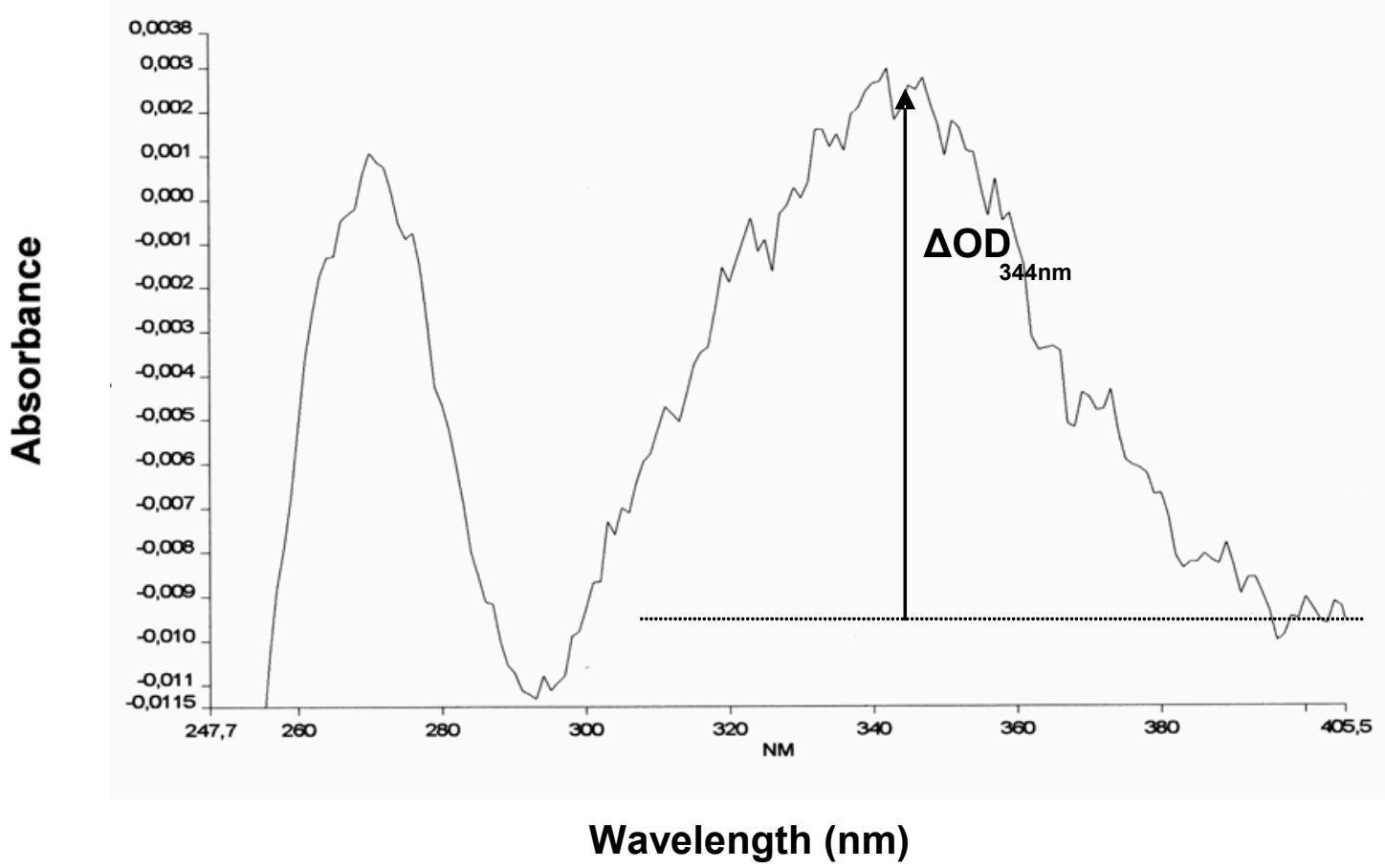

Figure 3: Spectrophotometer characterization of GST-DPDPB coupling. 


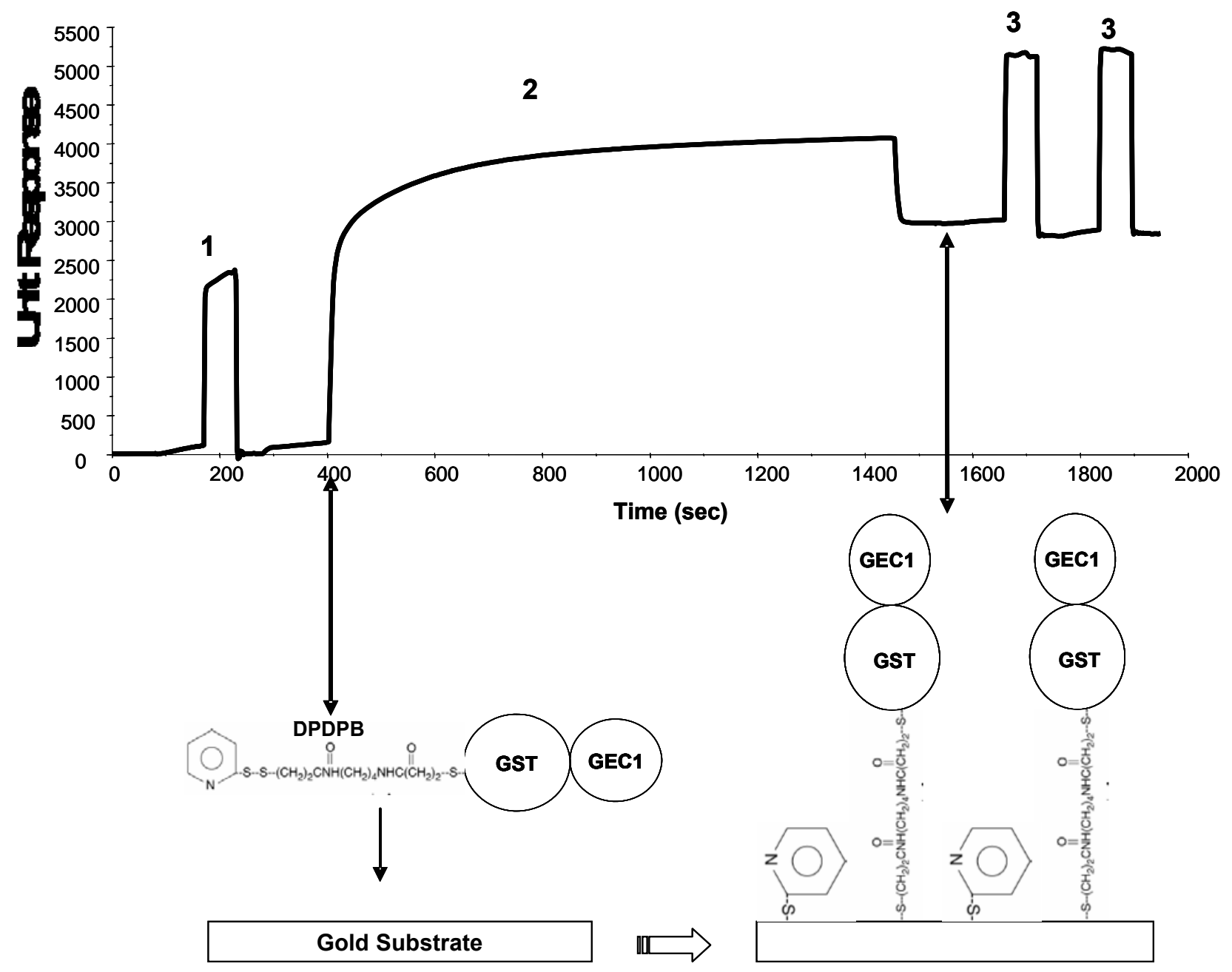

Figure 4: Self Assembly of "DPDPB -GST-GEC1" complexes onto gold sensor chip. 


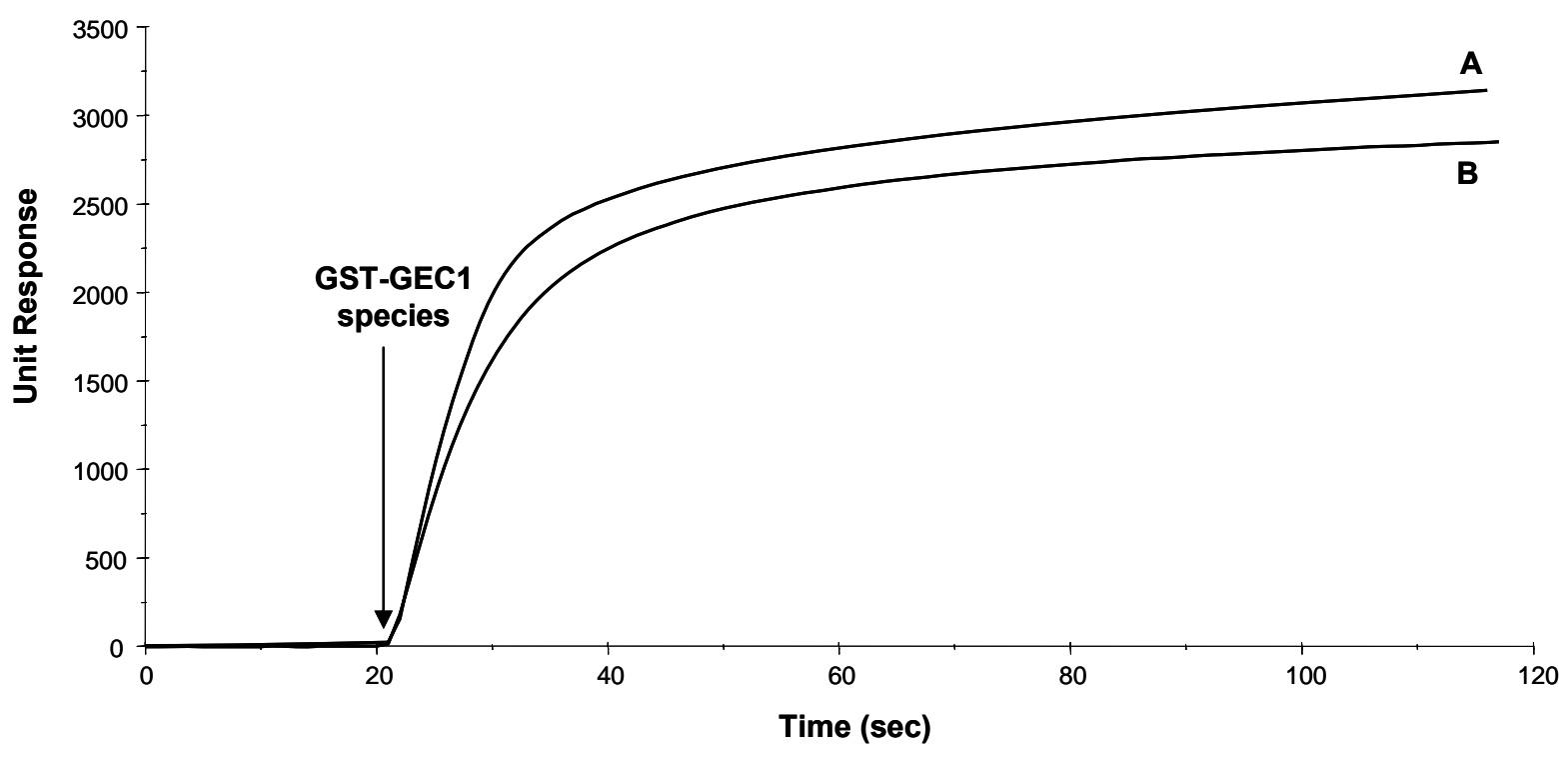

Figure 5: Superimposition of two GST-GEC1 immobilization strategies onto sensor chips. 


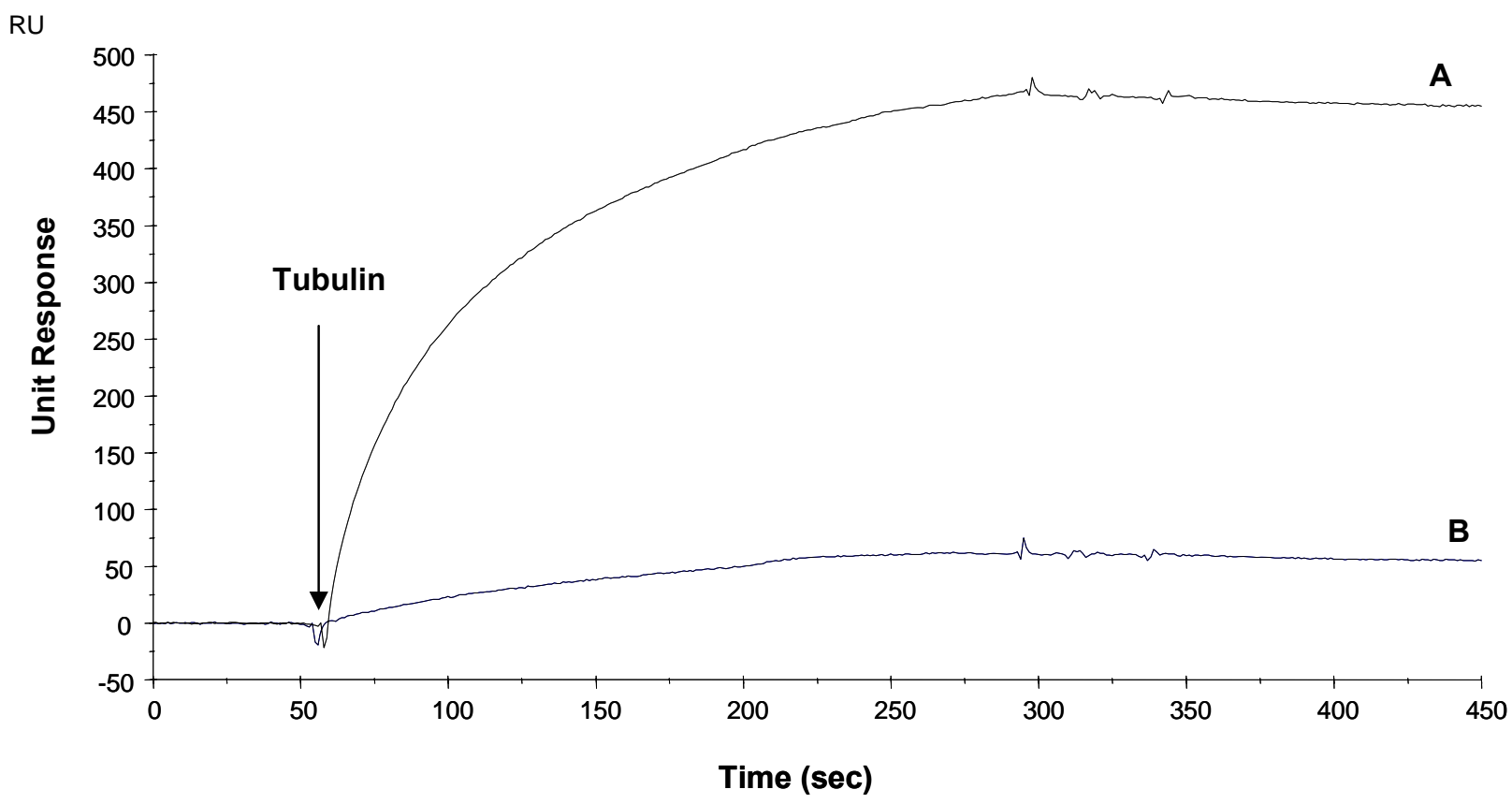

Figure 6: Specific interactions between tubulin and self-assembled DPDPB-GST-GEC1 complexes. 


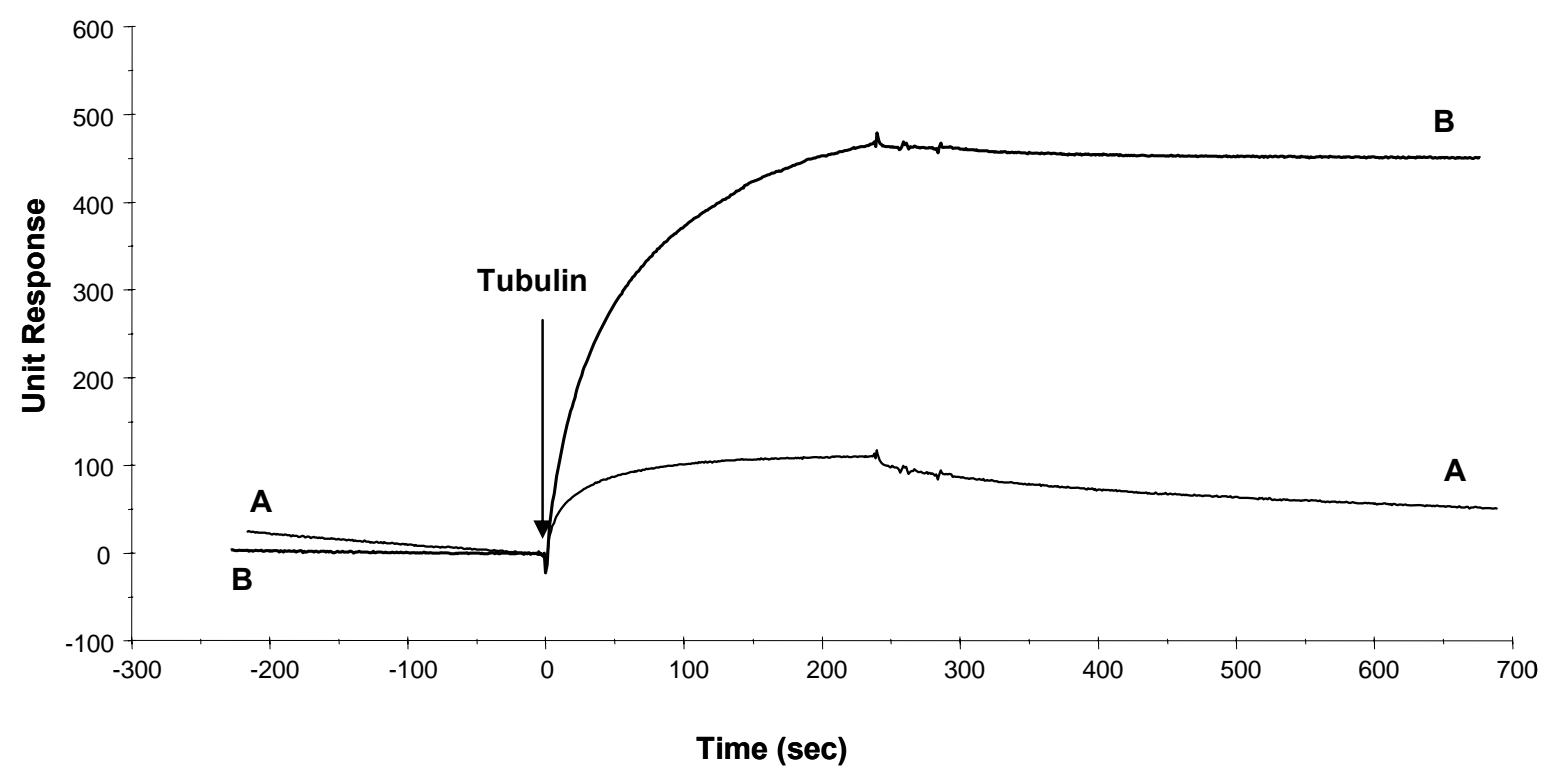

Figure 7: Comparisons of interaction levels of tubulin with two different GST-GEC1 substrates. 